\title{
La política lexicográfica actual de las academias de la lengua española: el caso del Diccionario de americanismos (ASALE, 2010)
}

\section{Daniela Lauria \\ InstitutodeLingüistica,FFyL,UniversidaddeBuenosAires/ \\ CONICET}

\section{RESUMEN}

Este trabajo analiza un acontecimiento político lingüístico singular en el marco de la Nueva política lingüística panbispánica (RAE y ASALE 2004): la publicación del Diccionario de americanismos (2010). Se adopta una perspectiva glotopolítica que considera los diccionarios como intervenciones en el espacio público del lenguaje, advirtiendo la relación que estos entablan con requerimientos históricos más amplios. La obra estudiada opera como un gesto complementario de la idea de "español global", que iría en detrimento de variantes léxicas concebidas como localismos. Es decir, ambos modelos de lengua, con énfasis en lo global o en lo local según el caso, argumentos y discursos metalingüísticos diferentes, participan de un juego signado por los mismos intereses económicos, ansiosos de captar un mercado más rentable.

Palabras clave: política lexicográfica académica del español, americanismos, globalización léxico hispánico, mercado 


\begin{abstract}
This paper analyzes a singular political-linguistic event in the framework of the New panbispanica language policy (RAE y ASALE 2004): the publication of the Dictionary of Americanisms (2010). One glottopolitics perspective that considers dictionaries as interventions in public space of language, noting the relationship they establish with broader historical requirements is adopted. The work under study operates as a complementary gesture of the idea of "global Spanish" which would undermine lexical variants conceived as localisms. That is, both models of language, with emphasis on the global or local as appropriate, different meta-linguistic arguments and discourses, participate in a game denoted by the same economic interests, eager to capture a more profitable market.

Keywords: Spanish academic lexicographical policy, americanisms, globalization of the Spanish lexicon, market
\end{abstract}

1. Introducción: datos contextuales, áreas idiomáticas y la política lingüística panhispánica

En varios de sus últimos libros, el influyente sociólogo y filósofo polaco Zygmunt Bauman (1999 y 2005) asegura que la globalización puede entenderse como una gran transformación que ha afectado, por igual, a las estructuras estatales, las relaciones interestatales, las subjetividades colectivas, las condiciones laborales, la producción cultural, la vida cotidiana y los vínculos entre los seres humanos. El complejo universo de la globalización es, por consiguiente, un fenómeno económico, político, social, cultural, educativo, tecnológico y demográfico, que se caracteriza por un constante flujo y circulación de capitales transnacionales, facilitados por la fuerza, la omnipotencia y la universalización de los medios de información y de comunicación, los avances técnico-científicos y la creación de organizaciones supranacionales que, junto con los movimientos migratorios, acentúan la desterritorialización de divisas e inversiones.

Habermas ([1998] 2000) plantea la erosión de los límites nacionales no solo en la economía, sino también en el área de la cultura. 
Un hecho peculiar es que se produce una paradoja entre dos efectos aparentemente contrarios: por un lado, la homogeneización de bienes simbólicos que procura atravesar las fronteras nacionales circulando por todo el planeta. Por otro lado - y como reacción al hecho anterior-, se fortalecen los localismos o regionalismos que evidencian la heterogeneidad al interior de los órdenes nacionales.

Otro fenómeno es la desterritorialización cultural, que implica la ruptura (pero no la anulación), según García Canclini (1999 y 2004), de los recursos simbólicos de toda relación con la historia y con la memoria de los lugares geográficos y sociales establecidos por los Estados nacionales en tanto instancias privilegiadas de producción de sentido. De manera indirecta, afecta a las identidades nacionales que en función de ellos se consolidaron. ${ }^{1} \mathrm{La}$ desterritorialización, sin embargo, se complementa con un movimiento de reterritorialización. El mundo global contemporáneo no es un mundo "sin fronteras": es un mundo en el cual surgen incesantemente "nuevas fronteras" que redefinen las anteriores.

En síntesis, el planeta globalizado ha fundado nuevas correlaciones locales, nacionales, regionales e internacionales, que transforman los discursos y las prácticas.

Los efectos que trae aparejados la globalización no son ajenos al espacio público del lenguaje, en general, y tampoco al ordenamiento de las lenguas históricas, en particular. Las transformaciones planetarias actuales con sus progresivos ajustes y tensiones demandan, según lógicas diversas e, incluso, en pugna, nuevas regulaciones e

\footnotetext{
1 Para Ortiz (2009), la mundialización cultural se asocia con la globalización económica y técnico-tecnológica, pero no coincide con ella de manera lineal. Por eso, según su visión, los temas de identidad nacional siguen estando presentes. En un libro más reciente, el autor sostiene que la cultura global no ha producido, en absoluto, la disolución de las diferencias, sino que las ha expuesto o fortalecido: "El proceso de globalización se impone como algo concreto, pero las diferencias ya no serán percibidas como su contrapunto, por el contrario, se afirman en su interior [...]. En este caso, la oposición global-local deja de tener sentido" (Ortiz 2014: 140-141).
} 
intervenciones en el campo del lenguaje. ${ }^{2}$ Se torna indispensable, así, repensar el lugar que la(s) lengua(s) y el lenguaje ocupa(n) en el orbe contemporáneo a la luz de las (des)articulaciones que se producen persistentemente y contrastarlas con el rol que les cupo en la configuración del imaginario nacional en el contexto político, social y económico de apogeo de los Estados. A propósito, Arnoux explica:

En el largo proceso de construcción de los Estados nacionales, la lengua común se fue afirmando como uno de los aspectos que sostenía la existencia de la nación a medida que se implementaban los modos de extenderla en un territorio que clausuraba las fronteras. En ello colaboraron, entre otros, el aparato burocrático, la escuela y los medios gráficos. A la vez que la lengua común (y la cultura escrita) constituía una necesidad de las sociedades industriales y de las nuevas formas de participación política, se la presentaba como la manifestación más clara de la identidad cultural del pueblo de la nación que se vinculaba y expresaba sus opiniones a través de ella.

En las últimas décadas, el proceso de globalización, al requerir la conformación de entidades más amplias (por lo menos en el plano económico), ha cuestionado la supuesta homogeneidad y los límites de los Estados nacionales haciendo visibles las diferencias culturales internas y destacando la porosidad de las fronteras. Esto ha llevado, asimismo, a interrogar sobre el papel de las lenguas en la ampliación del espacio comunicacional, en las estructuras de mercado extendidas y en los modos de organización políticos. (2010:18)

El fenómeno descrito incide en el interior de los países interrogando la supuesta homogeneidad cultural y lingüística en la que se asentaban y obligando a discutir, entre otros aspectos, el estatuto y alcance de la lengua “oficial” y los lugares que se asignan a las otras lenguas hasta ese momento minoritarias y/o minorizadas (Arnoux

\footnotetext{
2 Steger (2009) desarrolla, según su enfoque, los cinco componentes centrales que caracterizan la globalización de las lenguas: (i) el número cada vez menor de lenguas en el mundo; (ii) las intensas migraciones; (iii) el desarrollo del turismo; (iv) el aprendizaje de lenguas extranjeras; y (v) la omnipresencia de los medios masivos de comunicación y de las nuevas tecnologías, en especial las digitales.
} 
y Bein 2010; Arnoux 2010 y 2011). Este fenómeno, denominado, para algunos autores, glocalización, ${ }^{3}$ perturba las identidades lingüísticas, ya que se trata de un movimiento dialéctico global-local que, a la vez que tiende a una homogeneización generalizada más allá de las fronteras instituidas, visibiliza (y promociona) la diversidad interior como rasgo esencial de la dinámica sociedad actual.

La profunda transformación que caracteriza al mundo de hoy, con la globalización como escenario, repercute en las prácticas lingüísticas y, por lo tanto, demanda nuevas actuaciones tanto en la gestión sobre el corpus (poniendo en jaque la relación entre una lengua unitaria y sus variaciones inherentes) como sobre el estatus y la adquisición. Las políticas lingüísticas integran un conjunto mayor de decisiones relativas al Estado, la integración regional y el mercado. Al respecto, la primacía de los intereses económicos ha desplazado la fuerza política de los Estados nacionales. Esto provocó que comenzara a emerger un nuevo agente vinculado con el mercado: los medios masivos de comunicación. ${ }^{4}$ Efectivamente, las empresas mediáticas, muchas transnacionales y asociadas con conglomerados editoriales, asumieron de forma remozada funciones del Estado como, por ejemplo, la de regular aspectos vinculados con el lenguaje, la lengua y el discurso, a través, en un primer momento, de la publicación de manuales de estilo.

Como expone Arnoux (2008b y 2014), las políticas lingüísticas efectivas en la actualidad son, así, resultado de acuerdos y tensiones

\footnotetext{
3 "Glocalización" es un neologismo devenido de la fusión de los términos globalización y localización.

4 Payer advierte que, una vez más en la historia, han cambiado las formas del lenguaje y de la subjetividad social. Afirma: "[...] en cada tiempo histórico hay enunciados que funcionan como fundamentales, en tanto máximas capaces de condensar el contenido que ejerce la «interpelación ideológica de los individuos en sujetos» para retomar la conocida expresión de Althusser” (2005: 14). La autora se basa en Haroche (1984), quien analiza el pasaje de la forma sujeto de la Edad Media (religioso) a la Edad Moderna (jurídico). Si en el marco del Estado moderno el texto que interpelaba era la Constitución Nacional, en el presente el mercado actúa como instancia de interpelación. Pero no está solo: los medios de comunicación y las nuevas tecnologías son también los grandes productores de sentidos de los sujetos (hoy devenidos consumidores) y de las lenguas.
} 
entre los imperativos de los Estados, de las integraciones regionales y de las zonas interiores de los Estados nacionales. En este contexto, ganan importancia las políticas de áreas idiomáticas, que, en general, corresponden a lenguas supercentrales -en la terminología propuesta por Calvet ([1974] 2005) en su modelo gravitacional- como el inglés, el portugués, el español y el francés, y disponen un reordenamiento y una distribución jerárquica y espacial que recuerda las zonas de influencia de los antiguos imperios. Se caracterizan por explicitar una voluntad poscolonial de gestión democrática de la lengua compartida, basada en una pretendida desterritorialización de la misma. Asimismo, explotan el potencial económico de las lenguas vinculándolas con el mundo empresarial a través tanto de las industrias de la lengua, de la cultura y del mundo editorial como de las propuestas de enseñanza. Uno de los problemas que suscitan radica en que se impone, por cuestiones funcionales, una determinada variedad lingüística (geográfica, social) por sobre otras en las operaciones transnacionales. Esta medida no es, en absoluto, natural, sino que tiene una base nacional, es decir, hay un centro desde donde se toman las decisiones. Son, en realidad, movimientos geopolíticos en los que despunta un Estado económicamente fuerte y con peso estratégico en función de sus intereses nacionales y de los de la integración que forma parte. La autora plantea que el desarrollo de las áreas idiomáticas, especialmente del español, del portugués y del francés, que se acentuó a partir de los años noventa del siglo pasado, buscó expandirse en todos los ámbitos en que eso fuera posible y disputar posiciones o complementarse con el inglés en tanto lengua hegemónica en varios planos. Estas grandes zonas idiomáticas dieron un nuevo aliento a las lenguas mayores, ya que su radio de acción excedió los campos económico, científico, empresarial, tecnológico o diplomático. Así, mostró la importancia de atender a la dimensión política: para su desarrollo y vitalidad necesitan construir un imaginario de lengua compartido, para lo cual apelan a (o callan) necesariamente ciertos lugares de la memoria discursiva.

En el caso de la lengua española, se vislumbran cambios de la orientación de la política lingüística desde 1990. De acuerdo con 
Del Valle (2007), el telón de fondo es la creciente participación de España en los principales foros internacionales y la entrada en la lucha por los tesoros del mercado económico global. A principios de los ochenta, el Partido Socialista Obrero Español (PSOE), a cargo del Gobierno, se enfrentó al reto de conducir a España hacia la modernidad después de una fuerte dictadura y de un aislamiento internacional prolongado. En 1986, el país ingresó a la organización que hoy es la Unión Europea, agrupamiento económico y político que adquiriría un creciente peso en la escena mundial. Por otro lado, una década más tarde, se asistió al despegue de empresas transnacionales de capital español, muchas de las cuales aterrizaron con sus inversiones en Latinoamérica, que se perfilaba como un mercado promisorio. En ese marco, el Gobierno español, como parte de una política de Estado, comenzó a propiciar y financiar, con la colaboración de un conjunto de empresas privadas y fundaciones, una serie de políticas lingüísticas para fomentar y difundir el idioma español. Por un lado, se creó el Instituto Cervantes (IC) en 1991, con el fin promocionar internacionalmente la lengua a través de su enseñanza como lengua extranjera. Por otro, se sumó al proyecto la histórica Real Academia Española (RAE), que renovó su misión y montó una política de corte panhispánico tanto hacia la lengua cuanto hacia su gestión.

El documento Nueva Política Lingüística Panhispánica (NPLP) $)^{5}$ se presentó oficialmente en el III Congreso Internacional de la Lengua Española (CILE) “Identidad lingüística y globalización” en Rosario en 2004 y fue firmado conjuntamente por la RAE y la Aso-

\footnotetext{
5 En el Congreso de la Lengua de Sevilla, en 1992, se percibe, como analiza Rizzo (2014), que la globalización impone la interrogación sobre el estatuto simbólico del español y sobre la norma lingüística. Esto provoca una demanda de las empresas de medios masivos de comunicación. En los discursos se evidencian críticas a las acciones o, mejor dicho, a las no acciones de las academias. Se cuestiona que las escasas tareas de codificación no se ajustaban a los tiempos que corrían. Este pedido se potencia en el I CILE en Zacatecas (1997), cuando se explicita la preocupación en el marco de la sociedad de la información y de las nuevas tecnologías. Como respuesta, se esboza un documento teñido con el espíritu del futuro "nuevo" panhispanismo.
} 
ciación de Academias de la Lengua Española (ASALE). ${ }^{6}$ El texto se propone legitimar los nuevos instrumentos lingüísticos que ya se habían confeccionado (Ortografía de 1999) o los que se estaban proyectando y mantener, en consecuencia, su lugar privilegiado como primordial agente estandarizador en el ámbito hispánico. La NPLP expresa las principales líneas de esta “pretendidamente” nueva política sobre el español. En ella, se establecen los lineamientos en torno a la renovada labor de las academias, y los parámetros de intervención sobre el corpus, con el fin de actualizar, siguiendo el ritmo de la globalización, los instrumentos lingüísticos y, de este modo, configurar el estatus de lengua internacional. La RAE se convirtió en una institución más moderna que no solo trataba de organizar un soporte técnico con prestigio histórico para el proyecto lingüístico-mercantil de España, sino que preparaba la consolidación de un dispositivo institucional que sirviera de base a la reactivación del ya antiguo movimiento (pan)hispanista. ${ }^{7}$ La RAE fortalecía la red de academias correspondientes, apostaba por desarrollar los proyectos normativos junto con sus pares y declaraba abrazar una norma en la que las variedades regionales de América valieran tanto como las peninsulares. Aspiraba a crear una imagen de armonía en una relación de hermandad "codo con codo" y "en pie de igualdad" superadora de diferencias:

6 En 1951, el presidente mexicano Miguel Alemán organizó el I Congreso de Academias de la Lengua Española. Pese a las discrepancias políticas entre las autoridades mexicanas y españolas, porque las primeras reconocían el gobierno republicano en el exilio, se acordó la constitución de la asociación, “cuyo fin es trabajar asiduamente en la defensa, unidad e integridad del idioma común, y velar porque su natural crecimiento sea conforme a la tradición y naturaleza íntima del castellano" (Guzmán 2010: 552). Una vez superadas las diferencias, la RAE se sumó a la asociación. Hoy, con la reforma del estatuto, la ASALE tiene una vida más activa. La coordinación la realiza la Comisión Permanente, compuesta por un presidente (el director de turno de la RAE), un secretario general electo entre los académicos americanos, un tesorero (un académico de la RAE) y dos vocales de las academias asociadas. Ver Del Valle (2013b), que rastrea las tensiones de su fundación al analizar los discursos a contrapelo de la versión oficial.

7 A partir de la segunda mitad del siglo XIX, la RAE fomentó primero el nombramiento de académicos americanos correspondientes y luego la creación de academias americanas asociadas a la central. 
Las funciones atribuidas tradicionalmente a las Academias de la Lengua consistían en la elaboración, difusión y actualización de los tres grandes códigos normativos en los que se concentra la esencia y el funcionamiento de cualquier lengua y que aseguran su unidad: la Ortografía, el Diccionario y la Gramática. Hasta hace algunos años, el modo de alcanzar esos objetivos se planteaba desde el deseo de mantener una lengua "pura”, basada en los hábitos lingüísticos de una parte reducida de sus hablantes, una lengua no contaminada por los extranjerismos ni alterada por el resultado de la propia evolución interna. En nuestros días, las Academias, en una orientación más adecuada y también más realista, se han fijado como tarea común la de garantizar el mantenimiento de la unidad básica del idioma, que es, en definitiva, lo que permite hablar de la comunidad hispanohablante, haciendo compatible la unidad del idioma con el reconocimiento de sus variedades internas y de su evolución. (RAE y ASALE 2004: 3)

El desenmascaramiento de la dimensión ideológica de la NPLP ha sido un tema altamente estudiado por la crítica especializada en los últimos años (Mar-Molinero 2000; Del Valle y GabrielStheeman 2004; Del Valle 2007; Arnoux 2008b; Lauria y López García 2009; Paffey y Mar-Molinero 2009; Senz y Alberte 2011; Fanjul 2011; Del Valle y Villa 2012; Arnoux 2014; Lara 2015; Greußlich 2015). En particular, se puede sintetizar en tres los ejes desde los cuales se la ha abordado: (i) la gestión pretendidamente “colectiva y democrática” de la norma y el pasaje de un régimen de normatividad monocéntrico y unitario a uno pluricéntrico y/o panhispánico; (ii) la atención y el tratamiento otorgados a la diversidad: aceptación, inclusión y regulación de las variedades internas inherentes a la lengua (tanto geográficas como sociales), y la defensa de la unidad del español; y (iii) la lengua como recurso económico.

Los resultados de dichos estudios críticos demuestran que la NPLP expresa cabalmente una política de área idiomática, que algunos autores llaman "hispanofonía". ${ }^{8}$ Para todos, es una 8 Para Del Valle (2007), la Hispanofonía es una ideología lingüística. Durante
años, la literatura prefirió el término Hispanidad, que alude a una entidad abstracta 
construcción discursiva basada en la presunción de una comunidad de países que comparten la lengua para lograr la proyección internacional del español con una finalidad económica. En efecto, la NPLP no pasó de la mera manifestación de gestión democrática de la lengua compartida. Lejos de fomentar una distribución equitativa y multilateral de las funciones en la estructura organizativa y autoral en los nuevos instrumentos lingüísticos, así como también en la descripción de los rasgos lingüísticos de las distintas variedades del español, continúan reproduciéndose las antiguas jerarquías en la toma de decisiones, sosteniendo España una clara centralización gracias a la colaboración económica de una red de instituciones españolas y al apoyo de ciertos sectores latinoamericanos.

De acuerdo con Del Valle (2007), la RAE detenta la autoridad central de esta política idiomática de área, cuyo poder simbólico se sustenta en acciones retóricas que giran, para la configuración del imaginario colectivo, en torno de los siguientes ideologemas: la lengua española como concordia que borra la imposición sufrida por la conquista y la colonización; la lengua española como lengua internacional que excede las ataduras nacionales, es decir, una lengua sin territorio, sin historicidad y sin memoria; y la lengua española como producto rentable. Se busca instalar la idea de una lengua asociada al desarrollo económico y a valores universales de comunicación más que identitarios, que trasciende los intereses contingentes de un determinado Estado. No obstante, sus trabajos descubren que siguen con plena vigencia las pautas del nacionalismo, español en este caso. Pese a recusar el nacionalismo lingüístico (expresado en la fórmula "Un Estado, una nación, una lengua”), la NPLP resulta, de hecho, un tipo de posnacionalismo:

a la que se le atribuye existencia real. Hispanofonía, por su parte, se extiende a partir de los trabajos de Del Valle (2007) y de Hamel (2004), que con el sufijo -fonía (inspirados en la Lusofonía, la Francofonía, la Anglofonía) se remite a la idea de lengua compartida. Según estos autores, las distintas -fonías se construyen a partir de Estados nacionales que ayer fueron imperios y que hoy (pese a las crisis) son económicamente fuertes para intentar captar mercados lingüísticos inter y transnacionales. 
interesa y beneficia en particular a las estrategias geopolíticas y económicas de España, cuna del sostén político, financiero y técnico.

En este artículo nos interesa indagar, en el marco de la política lexicográfica llevada adelante por la RAE y la ASALE expresada en el apartado "El proyecto lexicográfico integrado" de la NPLP, el primer diccionario académico general de americanismos:

Esa base de datos relacional (la nueva forma de trabajar con el $D R A E$ ) es también, quizá incluso sobre todo, el recurso con el cual se hace posible avanzar un poco más. Hace ya mucho tiempo que las Academias han venido manejando la idea de que sus proyectos lexicográficos individuales forman parte de un conjunto más amplio, de una estructura global en la que cada elemento desempeña un cierto papel y encuentra su sentido. Por citar un caso claro, la publicación de un diccionario histórico supone que el $D R A E$ quedaría automáticamente liberado de la obligación de seguir manteniendo una buena parte de su lemario: el constituido por palabras o acepciones que ya no están en uso, pero que deben permanecer en él mientras la generalidad de los lectores hispánicos no disponga de otra obra en la que puedan consultar su significado. Gracias a que el $D R A E$ es ya en origen una base de datos relacional, las conexiones con otros proyectos como el Diccionario panbispánico de dudas, el Diccionario del estudiante o el Diccionario académico de americanismos resultan ahora realmente simples, con lo que se produce una notable economía de medios y, sobre todo, un considerable aumento de la congruencia entre los diversos proyectos, tan difícil de mantener por los procedimientos tradicionales.

Se hace, pues, posible, gracias a los recursos y procedimientos electrónicos de que podemos disponer en la actualidad, no ya concebir y desear, sino llevar a cabo un auténtico proyecto lexicográfico integrado, en el cual cada obra cobre sentido en el interior del conjunto total al que pertenece y que se defina por su relación con las demás (...). (RAE y ASALE 2004: 4-5) 
Como se ve en el fragmento citado, el DRAE9 (con 23 ediciones a cuestas: la última del 2014 y que actuó —y actúa — como la pauta de referencia (absoluta) del quehacer lexicográfico monolingüe del español) es la pieza clave sobre la cual gravitan todas las otras obras que forman parte del proyecto:

- RAE y ASALE, Diccionario panbispánico de dudas. Madrid: Santillana, 2005

- RAE y ASALE, Diccionario esencial de la lengua española. Madrid: Espasa, 2006

- ASALE, Diccionario de americanismos. Madrid: Santillana, 2010

- RAE, Diccionario del estudiante. Madrid: Santillana, 2005 y 2011

- RAE y ASALE, Diccionario práctico del estudiante. Madrid: Santillana, 2007 y $2012^{10}$

El Diccionario de americanismos (DA) es el foco de atención del presente trabajo, cuyos objetivos son comprender y explicar las implicancias glotopolíticas, por un lado, de la modalidad lexicográfica adoptada: diccionario general de americanismos ejecutado a partir de la aplicación del método diferencial en relación con el supuesto “español general”, medido a partir de la vara que impone el DRAE sobre la base de la variedad utilizada por determinados sectores (cultos) de la región centro-norteña de la península; ${ }^{11}$ por otro,

\footnotetext{
9 En algunos documentos de la RAE se rebautizó el DRAE como DILE (Diccionario de la Lengua Española). Este cambio atiende al aporte de las restantes academias en su confección.

10 El Diccionario práctico del estudiante es una versión del Diccionario del estudiante, dirigida a los alumnos de los países hispanoamericanos. Sobre los diccionarios escolares académicos, ver Lauria (2013).

11 Decimos “supuesto español general” porque esta modalidad no está registrada en ninguna obra y nadie sabe de qué se está hablando exactamente al utilizar ese sintagma. En términos lexicográficos rigurosos, solo por este motivo, ya es imposible hacer un diccionario diferencial, que por definición parte de un conjunto dado de unidades léxicas utilizadas en un lugar determinado por hablantes concretos.
} 
del imaginario social convocado mediante el léxico consignado. El punto de partida es que el DA, que intenta ser útil a las economías desregionalizadas con el afán de impulsar un léxico común, opera como un gesto complementario del denominado "español global" (que, conceptualmente, va en detrimento de las variantes léxicas marcadas localmente), esbozado por Humberto López Morales, secretario general de la ASALE (1994-2015) y director responsable justamente del DA, en su libro La globalización del léxico bispánico de 2006. Ambos modelos de lengua, en general, y del léxico, en particular, con énfasis en lo global o local según el caso, con argumentos, inclusiones y exclusiones en discursos metalingüísticos distintos, constituyen estrategias que participan de un juego signado por los mismos intereses económicos, ansiosos de captar un mercado más rentable. ${ }^{12}$

\section{El enfoque glotopolítico}

La investigación se inscribe en el enfoque glotopolítico (Arnoux 2008a; Del Valle 2007; Arnoux y Del Valle 2010; Del Valle 2013a; Arnoux y Nothstein 2014), que aborda, mediante el análisis discursivo de materiales de archivo histórico (próximo o distante), las prácticas, las ideologías y las intervenciones en el espacio público del lenguaje, atendiendo a la relación que estas entablan con transformaciones y requerimientos sociohistóricos más generales, así como a su participación en la construcción de subjetividades. Arnoux puntualiza:

Quiero agradecer, en este punto y en otros, al investigador José Carlos Huisa Téllez por las observaciones precisas que oportunamente realizó a una primera versión del presente trabajo.

${ }_{12}$ El DA fue objeto de reseñas críticas realizadas desde la lexicografía teórica (o metalexicografía). A propósito, ver Cerrón-Palomino (2010) y Lara (2012), quienes coinciden en descalificar la metodología empleada debido a que arrastra las fallas decimonónicas de la práctica diccionarística. Un estudio interesante que discute el lugar de los diccionarios de -ismos en el marco de una lengua pluricéntrica es el de Zimmermann (2013). 
[la Glotopolítica] [...] estudia, entonces, las ideologías lingüísticas y las intervenciones en el espacio público del lenguaje asociándolas con posiciones sociales y espacios institucionales e indagando en los modos en que aquellas participan en la instauración, reproducción o transformación de entidades políticas, relaciones sociales y estructuras de poder tanto en el ámbito local o nacional como regional o planetario. (2008a: 18)

Adoptar esta perspectiva implica tener en cuenta las complejas relaciones entre el lenguaje, la política, el Estado y la sociedad civil. De cuño fuertemente discursivo e historicista, está atenta a la heterogeneidad y a la manifestación del conflicto: el lenguaje es considerado menos como una entidad fija que como un espacio donde se exhiben roces y se dirimen posiciones políticas en un momento histórico determinado siempre sometido a un juego de fuerzas contrapuestas. Los discursos metalingüísticos, que intentan estabilizar la lengua aunque esta siempre encuentre la forma de resbalarse, se examinan como acontecimientos intrínsecamente históricos, que exceden los límites del campo meramente lingüístico y se insertan en un entramado de relaciones amplio con exigencias que se producen en (o desde) los ámbitos político, social, económico, cultural, educativo, tecnológico y demográfico, y en los que intervienen determinados agentes (personas e instituciones que representan y/o responden a ciertos intereses). De ahí que el diccionario sea considerado, antes que un instrumento lingüístico de descripción o de prescripción que instituye normas, fija un estándar, define el léxico y propone una forma ortográfica, como un instrumento que establece y manifiesta relaciones sociales y formas de poder. Acarrea, por ende, desigualdad en la medida en que legitima y reproduce principios y valores dominantes que se imponen y que regulan las relaciones entre distintos grupos sociales.

En lo que sigue, reseñaremos sucintamente el derrotero histórico de los diccionarios generales de americanismos y expondremos sus principales atributos. Seguidamente, nos centraremos en el DA: los pormenores del relato de la historia del proyecto académico, la descripción de sus rasgos cardinales y el examen del despliegue 
discursivo lexicográfico, en especial las zonas más sensibles a las condiciones de producción en cuanto son expresión de posicionamientos siempre histórica, social y políticamente situados. Luego, discutiremos la relación dialéctica entre la recopilación de americanismos léxicos, y el diseño y promoción de un español global, sobre todo en el plano del vocabulario, por presión de los mercados globalizados. En ese punto, identificaremos las ideologías lingüísticas anudadas a esos modelos de lengua.

3. Breves apuntes en torno a los diccionarios generales de americanismos

El género lexicográfico diccionario general de americanismos (repertorio monolingüe, semasiológico y menos prescriptivo que descriptivo, que registra, a través del método contrastivo, el vocabulario "particular” del español de América, concebido este como un bloque homogéneo frente al español de España) emerge en las primeras décadas del siglo xx. Irrumpe con posterioridad a la aparición de la modalidad "diccionarios de provincialismos o regionalismos del español de América” que compendian el léxico "privativo" por países o regiones. Parece difícil rebatir que esta última forma diccionarística — de provincialismos o por países- que resalta las diferencias está, en su mayor parte, ligada a la construcción y consolidación de los Estados nacionales desde la segunda mitad del siglo XIX y se intensifica con fuerza en las primeras décadas del siglo $\mathrm{xx}$, alrededor de las conmemoraciones por los centenarios de las independencias de los países americanos. Tal como sugiere Lara en varios de sus ineludibles trabajos (1996, 1997, 2004 y 2013), los hubo inicialmente más cercanos a un perfil normativo (registro de voces calificadas como barbarismos, vulgarismos, disparates, errores), a la "conciencia del desvío" en palabras del investigador mexicano, y, con el paso del tiempo, más afines a motivos de orden simbólico. ${ }^{13}$

13 Es necesario recordar que el Diccionario provincial de voces cubanas de Esteban Pichardo (1836) está a medio camino entre el diccionario y la enciclopedia. Su trabajo 
Ahora bien, esta modalidad de diccionarios - de alcance nacional, regional o general-, que toma como parámetro de referencia el lemario del $D R A E$, sigue vigente a lo largo de todo el siglo xx y perdura en lo que va del XXI, fundamentalmente como producción de las academias americanas correspondientes. ${ }^{14} \mathrm{Ha}$ contribuido a conformar una identidad lingüística funcional a la ideología de lengua central y variedades periféricas. En los últimos años, concomitantemente a la publicación de diccionarios parciales, aparecieron los primeros integrales del español de la Argentina y de México, ${ }^{15}$ que revisten de otros valores a la variedad nacional y que, por eso, dislocan la tradición lexicográfica hegemónica en América de habla española ${ }^{16}$ que solo daba cuenta de la especificidad lingüística.

La bibliografía crítica que se ocupa de los diccionarios generales de americanismos proviene primordialmente de disciplinas tales como la historia de la lengua en América, la dialectología y, en especial, la metalexicografía, cuyo interés radica en la indagación de la selección de la macroestructura y, más precisamente, en los criterios de definición y delimitación del conceptualmente "huidizo" objeto discursivo americanismo y sus términos asociados: "indigenismo", "marinerismo en tierra”, "arcaísmo", "neologismo", estos últimos con o sin cambio semántico. ${ }^{17}$ Mientras que algunas obras abogan por seguir un criterio etimológico (palabras nacidas en suelo

es anterior a la aparición de las ideas normativas sobre los llamados americanismos. Lo mismo sucede con el Vocabulario rioplatense de Francisco J. Muñiz de 1845 y el Proyecto de Diccionario de Argentinismos de la Academia Argentina de Ciencias, Letras y Artes (1875-1879). Ver al respecto de esta última obra Lauria (2012a).

14 Entre otros, el Diccionario del habla de los argentinos (2003 y 2008) de la Academia Argentina de Letras, el Diccionario de mexicanismos (2010) de la Academia Mexicana de la Lengua y el Diccionario de uso del español de Chile (2010) de la Academia Chilena de la Lengua.

15 Nos referimos al Diccionario integral del español de la Argentina (Tinta Fresca, 2008) y al Diccionario del español de México (El Colegio de México, 2010). Está en proceso de elaboración el Diccionario integral del español de Cuba (Instituto de Literatura y Lingüística José Antonio Portuondo Valdor de La Habana).

16 Para ver las ideologías lingüísticas que se materializan en dichas obras, ver Lauria (2012b). Zimmermann (2003, 2012 y 2013) abordó también la cuestión.

17 Es un texto clásico de matriz dialectológica Rona (1969). 
americano), otras recuren a principios más amplios, de tipo descriptivo y sincrónico, que den cuenta del uso efectivo de la lengua (inclusión de préstamos, calcos, extranjerismos). ${ }^{18}$ En lo que atañe a la microestructura, los estudios metalexicográficos esclarecen la clase de definición (lingüística o enciclopédica), las marcas de uso, el orden de las acepciones según la etimología o la frecuencia de uso, y las fuentes consultadas. En términos generales, la serie de diccionarios de americanismos evidencia un saber léxico y lexicográfico estabilizado de tipo folklórico, en el que predominan los campos semánticos concernientes a la flora, fauna, costumbres, comidas, vestimentas, danzas, instrumentos autóctonos, entre otros.

Queda por efectuar, empero, un estudio exhaustivo de los diccionarios generales de americanismos desde el enfoque glotopolítico, ${ }^{19}$ interesado en la comprensión del sentido histórico de cada una de las obras y en el relevamiento de las regularidades y los desplazamientos más significativos desde sus inicios y hasta la actualidad. Provisoriamente es posible conjeturar que su emergencia responde oponiéndose al movimiento expansionista e intervencionista estadounidense con la anexión, primero, del norte de México y después con el triunfo en la guerra contra España. A causa de estos hechos, germinó un discurso antiimperialista que se empeñó en valorar la cultura hispánica. Muchos escritores e intelectuales de fines del siglo XIX y comienzos del XX construyeron, por ende, un imaginario panamericano que trascendiera las fronteras nacionales y envolviera a todos los países en una matriz de hermandad a través de la lengua compartida desde México a la Argentina y, a su vez, con España. Paradójicamente, se volvía con aprecio a la antigua metrópolis, antes resistida. En tales circunstancias, asoma, así, el panhispanismo, no sin polémicas y debates, en tanto estrategia de acercamiento entre

18 Trabajos metalexicográficos son Gutemberg Bohórquez (1984), Haensch (1986 y 1994), Werner (1990, 1994 y 2001) y López Morales (2008).

19 Entre los estudios realizados desde el enfoque glotopolítico sobre diccionarios nacionales, v. Lauria (2011, 2012a, 2012b y 2014) para el caso argentino; Huisa Téllez (2013 y 2014) para el peruano; Chávez Fajardo (2013 y 2014) y Rojas (2014 y 2015) para el chileno; Coll (2012 y 2015) para el uruguayo; entre otros. 
España y América a través de varias vías: las relaciones diplomáticas, la tesis de que la cultura hispanoamericana era la española y la que, con el tiempo, derivaría en un mercado económico. ${ }^{20}$ Rama propone una línea argumental que muestra la importancia que adquirió la "batalla de la lengua", por una serie de polémicas que se suscitaron especialmente en la región del Río de la Plata: ${ }^{21}$

A lo largo del siglo XIX, tanto en América española como en la España que se ocupa de la vida intelectual de las Américas, se libra una sostenida polémica sobre los problemas de la lengua castellana y su uso en América, que es un episodio importante en el campo de las relaciones culturales entre ambos continentes. [...] A los hispanoamericanos les interesa que la lengua sea un lazo cultural entre sus propias sociedades (con independencia de España) y que, por razón de las divisiones políticas que acarrea la descolonización, «no explote la unidad lingüística en lenguas diferentes», como en su tiempo sucediera con el latín, a la caída del Imperio romano. Naturalmente, los «españolistas» conservadores o «restauradores» hispanoamericanos creen que la lengua debe ser conservada en los estrictos términos del clasicismo purista, como un puente más entre España y sus antiguas colonias. La apertura mundial que vive América, la influencia india y africana, los usos populares, en los hechos renuevan activamente y en forma muy dinámica la lengua de los hispanoamericanos. Los «provincialismos», «regionalismos» o, como terminará llamándoseles «americanismos» serán inventariados y conservados, aparte de los neologismos derivados de experiencias nuevas y de renovadas necesidades económicas, culturales e ideológicas. (1982: 116)

A solo efecto de su mención, los diccionarios generales de americanismos son los siguientes:

- 1912. Americanismos de Miguel de Toro y Gisbert publicado en París. No se trata de una obra lexicográfica, sino de estudios monográficos con información sobre el léxico. ${ }^{22}$

20 V. sobre este tema, Sepúlveda (2005).

21 V. también Del Valle y Gabriel-Stheeman (2004). Glozman y Lauria (2012) compilan los debates sobre la lengua en la Argentina.

22 Un antecedente es la Colección de Voces americanas del historiador Manuel Trelles (1853), publicada en El Plata Literario. La obra se proponía corregir los 
- 1925 (otras ediciones corregidas: 1931 y 1946). Diccionario de americanismos de Augusto Malaret. Se trata de la primera obra lexicográfica de este tipo stricto sensu. No es un dato menor remarcar que la primera edición se publicó en Puerto Rico. Como se sabe, los puertorriqueños son ciudadanos estadounidenses desde 1917. Aunque su vínculo con Estados Unidos es similar a la de un estado miembro, se le permitió la redacción de una constitución para el manejo de los asuntos internos, que está, sin embargo, sujeto a los poderes plenos del Congreso estadounidense. Esto significa que el poder de soberanía recae en el país del norte y los poderes existentes en la isla, al no gozar de protección en la constitución estadounidense, son revocables. Lo que se halla en juego en este gesto glotopolítico es la defensa del español, puesto que es la lengua materna de gran parte de la población, además del lazo cultural con España y no con Estados Unidos.

- 1942. Diccionario general de americanismos de Francisco Santamaría (México, Robredo).

- 1966 (otras ediciones: 1983 y 1989). Diccionario manual de americanismos de Marcos Augusto Morínigo (Buenos Aires, Muchnik). Su excepcionalidad estriba en que el autor contaba con una formación especializada, ya que había sido discípulo de Amado Alonso en el Instituto de Filología de la Universidad de Buenos Aires. Otras ediciones corregidas son el Diccionario del español de América (Madrid, Anaya y Muchnik, 1993) y el Nuevo diccionario de americanismos e indigenismos (Buenos Aires, Claridad, 1998) a cargo de su hijo Marcos Alberto Morínigo Vázquez-Prego.

- 1973 (2 a edición en 1975). Diccionario de americanismos de Alfredo Neves (Buenos Aires, Sopena).

americanismos incorporados al Nuevo diccionario de la lengua castellana (1846) del español Vicente Salvá. Tiene en total 285 vocablos. Las voces registradas son de empleo general en todo o en gran parte del continente. Ver Weinberg (1976). 
- 1980. Diccionario temático de americanismos de Miguel Arias de la Cruz (León, Everest).

- 1982/3. Volumen Americanismos. Diccionario ilustrado de la lengua española (Barcelona, Sopena).

- 1987. Tomo Americanismos. Diccionario Everest (León, Everest).

- 1990. Diccionario de americanismos. ABC of Latin American Spanish de Brian Steel (Madrid, Sociedad General Española de Librería).

- 1996. Diccionario práctico de americanismos (León, Everest).

- 1997 (otras ediciones: 2000 y 2006). Diccionario de bispanoamericanismos no recogidos por la $R A E$ de Renaud Richard (coord.) (Madrid, Cátedra). Esta obra presenta dos novedades: incluye voces del español de los Estados Unidos y aumenta notablemente el acervo particular americano, recogiendo el léxico usual. Esto no rivaliza con el hecho de reunir también vocablos de cuño folklórico. ${ }^{23}$

\section{El Diccionario de americanismos (ASALE 2010)}

4.1. El relato de la historia del proyecto

En 2005, la ASALE, junto con la Academia Argentina de Letras (AAL), publica el libro Diccionario académico de americanismos. Presentación y planta del proyecto. El primer texto titulado "Preliminar” está firmado por el entonces presidente de la AAL, Pedro Luis Barcia, quien aduce que el proyecto es un "notable e

23 Se debe mencionar el proyecto de la Universidad de Augsburgo, Alemania, bajo la dirección de Günther Haensch y de Reinhold Werner. El primer proyecto, denominado Nuevo diccionario de americanismos, dio como resultado sendos diccionarios de Colombia, Argentina y Uruguay. La segunda parte "Diccionarios contrastivo del español de América” produjo el Diccionario del español de la Argentina y el Diccionario del español de Cuba. Debido a que no son diccionarios generales de americanismos quedan fuera de la serie. 
impar emprendimiento lexicográfico" (ASALE 2005: 5). A renglón seguido, en la "Presentación", suscrita por Repsol/YPF, ${ }^{24}$ sobresalen dos fragmentos elocuentes respecto de la relación entre España y América en cuanto idea nuclear de la política panhispánica. Se ostenta la alianza tejida entre las academias y ciertas empresas privadas de capital español con intereses transnacionales: "Y este proyecto llega en el momento en que los lazos entre España y los países hispanoamericanos se consolidan y florecen en múltiples intercambios espirituales y materiales" (López Morales 2005: 7). Y continúa en el párrafo subsiguiente con la misma orientación argumentativa:

La edición del Diccionario Académico de Americanismos (DAA) corresponde, de acuerdo a la visión de nuestra época, a una etapa de la historia en que los países afianzan sus culturas al mismo tiempo que encuentran nuevas formas de asociación mutuamente provechosas. (López Morales 2005: 7) ${ }^{25}$

En los dos escritos que siguen, Humberto López Morales figura como autor. En el primero, "Presentación del proyecto de elaboración del Diccionario Académico de Americanismos de la Asociación de Academias de la Lengua Española", menciona la causa central que motiva el proyecto: los diccionarios generales de americanismos publicados hasta la fecha no ofrecen "el retrato auténtico y cabal de este vocabulario” (López Morales 2005: 14). Asimismo, agrega una segunda razón en cuanto a que dichos diccionarios son, consiguientemente, insuficientes para el lector de textos hispanoamericanos. El nuevo diccionario se convertirá en una herramienta que permitirá seleccionar las voces que deben estar presentes en el DRAE, "que hasta hace muy poco publicaba la Real Academia Española en

${ }^{24}$ La empresa argentina YPF (Yacimientos Petrolíferos Fiscales) se dedica a la exploración, explotación, destilación, distribución, y venta de petróleo y de sus productos derivados. En 1999, fue adquirida por la compañía española Repsol. Trece años después, en 2012, fue expropiada por ley del Congreso Nacional.

25 En la "Tábula gratulatoria" del DA resulta llamativo cómo se le retribuye a Repsol su mecenazgo: "especialmente interesada en enaltecer los valores de España del otro lado del Atlántico” (ASALE 2010: XXIX). 
solitario, pero que ahora es una obra panhispánica común” (López Morales 2005: 15). De igual forma, tal como se verá más adelante, anticipa que la globalización es un factor clave en los cambios que experimentará el léxico:

Estamos en el momento crucial para recoger todo este caudal léxico americano, antes de que el creciente proceso de globalización léxica, imprescindible para la creación de un español 'internacional', ya muy fortalecido, termine por someterlos a un creciente proceso de mortandad. (ASALE 2005: 15)

Finalmente, el autor refuerza su propuesta con argumentos teóricos y prácticos sobre las condiciones materiales para su concreción: gracias a la implementación de la NPLP se cuenta con financiamiento (interno, externo, público y privado) que posibilita el armado de un dispositivo institucional interacadémico con redes de comunicación y tecnológicas, que facilitan la labor conjunta a través de comisiones distribuidas por materias y zonas geográficas. Asimismo, la formación de recursos expertos desarrollada por la Escuela de Lexicografía Hispánica y la existencia de varios corpus de referencia (CREA, CORDE, CORPES XXI, NTLLE, entre otros $)^{26}$ habilitan la tarea.

El segundo texto, "Breve historia de un proyecto (1951-1996): el Diccionario Académico de Americanismos”, es un discurso proclive a mostrar el derrotero armónico del proyecto. López Morales organiza cronológicamente la narración mediante la lectura de las actas de los congresos de la ASALE dando cuenta de los avances y retrocesos de la empresa lexicográfica e identificando ciertos hitos a partir de un acontecimiento clave como es la fundación de la ASALE y la determinación de su órgano de gobierno en 1951 en México. Como resultado de lo discutido en el Congreso fundacional de la ASALE, ${ }^{27}$ la resolución XI postula, entre sus actividades,

\footnotetext{
26 Para consultar los recursos académicos, ver la página oficial de la RAE.

${ }^{27}$ La inclusión sistemática de americanismos en el DRAE, que se erige como el “diccionario oficial” de la lengua española, es un rasgo constitutivo de la ideología lingüística panhispánica y tiene una historia anterior a la fundación de la ASALE.
} 
la formación de un diccionario general de americanismos de carácter colegiado:

El Primer Congreso de Academias de la Lengua Española, resuelve: Encomendar a la Comisión Permanente nombrada por él mismo, que arbitre medidas y emprenda los trabajos necesarios para realizar, lo más pronto posible, la formación de un Diccionario de Americanismos. (López Morales 2005: 21)

En el II Congreso en Madrid en 1956, el académico uruguayo Adolfo Berro García propone la realización de un Gran Diccionario Hispanoamericano de la Lengua. El cambio de título no es menor puesto que de él podría inferirse de que se trata de una obra integral, con un efecto lexicográfico distante del que le ofrecería una obra que recogiera únicamente -ismos. No obstante, se funda en el método diferencial, ya que aclara que tendría como base el Diccionario manual ilustrado de la RAE y entraña como meta la inclusión de determinadas voces americanas en el DRAE.

En el V Congreso en Quito en 1968, se insiste, sin respuesta favorable, en la realización de un diccionario de americanismos, pero esta vez por iniciativa de la delegación de Puerto Rico. Lo mismo sucede en el VI Congreso en Caracas en 1972 y en Santiago cuatro años después. Es desde la década de 1980 y con más ímpetu en los

En el Diccionario de Autoridades (1726-1739) se incluyeron 125 términos procedentes de América. Como corolario de la creación de academias americanas, en la "Advertencia" de la duodécima edición del DRAE de 1884 se anuncia la participación de las sedes de Colombia, México y Venezuela. Con todo, en la nomenclatura no se percibe lo proclamado. Años más tarde, tiene lugar el "affaire Palma": en el marco del Congreso Literario Hispanoamericano (Madrid, 1892), el académico peruano Ricardo Palma asiste a las sesiones de la RAE. Allí presenta una serie de voces para que sean incluidas en el diccionario. Muchas son rechazadas por ser calificadas como neologismos inadmisibles. A raíz de este episodio, el autor escribe un artículo muy crítico: Neologismos y americanismos en 1896. Los argumentos que esgrime para la defensa son dos: el fluido intercambio con otros países y la universalización de la ciencia y la técnica. Otro suceso importante es la decimoquinta edición del DRAE de 1925, conocida como "la americana" debido a la entrada de gran cantidad de voces de ese origen. Esta edición modifica el título de la obra: pasa de "castellano" a "español". A partir de ahí, se alude continuamente en las "Advertencias” del DRAE al tópico de la cantidad de americanismos incorporados. 
noventa cuando revive el proyecto por iniciativa de López Morales y de Alfredo Matus (Academia Chilena de la Lengua) como sus máximos impulsores. En los considerandos de la resolución que se emite por el X Congreso en Madrid en 1994 se expresa:

En el momento presente, se hace más y más necesario que el $D R A E$ sea realmente el diccionario del español estándar. Ello exige, entre otros ajustes, liberarlo de localismos, lo cual lleva a redefinir la presencia de americanismos. En este sentido, puede pensarse, por ejemplo, que el futuro $D R A E$ deje de ser el lugar donde se recojan muchos americanismos que no cumplan con las condiciones de generalidad exigibles a un repertorio de la lengua estándar. De ser esto así, los regionalismos de uso en cada país de Hispanoamérica o en determinadas zonas supranacionales, tendrían cabida en el Diccionario Académico de Hispanoamericanismos”. (López Morales 2005: 35)

A tal fin, se convoca una reunión en Montevideo en 1996, en la que se despliegan los fundamentos de la planta (siguiendo las pautas actuales de la práctica lexicográfica: semasiológico, usual, dialectal y diferencial). Un hito capital en la historia del proyecto lo constituye el XI Congreso celebrado en Puebla en 1998, porque en él se aprueban los lineamientos que guiarán la obra y, de ese modo, se marca su inicio oficial. En el siguiente congreso, en Puerto Rico, se suscribe la base del diccionario.

\subsection{Descripción de la obra}

El DA se publicó en 2010 por la Editorial Santillana y se imprimió en Lima. Si bien está firmado solamente por la ASALE, la RAE puso a disposición las infraestructuras documental y tecnológica, los equipos centrales lexicográfico e informático, y el personal auxiliar en la sede de Madrid. La presentación oficial iba a efectuarse en el V CILE “América en la lengua española” en Valparaíso, pero no se pudo realizar debido al terrible terremoto que azotó a Chile unos días previos a la inauguración.

En todos los eventos de presentación se reitera una y otra vez que es una contribución a la conmemoración de los bicentenarios 
de las independencias de las repúblicas americanas, así como se destacan los méritos cualitativos y cuantitativos de la obra:

[...] constituye un repertorio léxico que pretende recoger todas las palabras propias del español de América, detallando al máximo la información relativa a las características geográficas, sociales y culturales del uso de cada una de las acepciones registradas. Contiene 70000 voces, lexemas complejos, frases y locuciones y un total de 120000 acepciones. (RAE s/a)

La voluminosa obra de un tomo tiene cuatro partes: la primera es el componente programático que está subdividida en ocho secciones; la segunda, el cuerpo del diccionario; la tercera, el índice sinonímico; y la cuarta, la serie de ocho apéndices. ${ }^{28}$

La dimensión programática abre con la "Presentación" a cargo de Víctor García de la Concha en tanto presidente de la ASALE, quien pone en evidencia la excepcionalidad de la obra:

Como es lógico, a las Academias americanas ha correspondido el protagonismo en la construcción de este Diccionario. Cada una de ellas se ha responsabilizado de su parcela de léxico con una dedicación esforzada y ejemplar. (ASALE 2010: $\mathrm{x}$ )

Unas líneas más abajo completa:

Por su parte, la Real Academia Española ha hecho posible que el Diccionario de Americanismos sea una realidad, procurando mecenazgos cuyas aportaciones económicas ha completado ella

28 Es indicativo que en los apéndices, es decir, en los márgenes del texto se introduzca la información que se compagina con los límites nacionales: gentilicios americanos distribuidos por país, provincias, capitales, ciudades importantes, regiones y suprarregiones. Además, se incluyen los gentilicios para extranjeros festivos y despectivos (máxime de países limítrofes). Otros temas son las nomenclaturas gubernamental, militar y monetaria, distribuidas también por países. Por último, debido al discurso tan en boga de lo políticamente correcto, al amparo, como es sabido, de las políticas de la identidad, y de respeto y defensa de la diversidad, que se impone con cada vez más peso y que afecta las representaciones y la visibilización de las lenguas que se hablan en una determinada región, tienen cabida los nombres de las etnias y lenguas indígenas vivas. Antes, su registro tenía un tinte exclusivamente folklórico, como lo sigue teniendo, por caso, el registro de hipocorísticos. 
de manera generosa, y prestando recursos humanos así como la infraestructura material y técnica necesaria (ASALE 2010: x).

Para terminar, “[t]odo ello es obra de las veintidós Academias asociadas en su trabajo al servicio de la unidad del español sin menoscabo de su rica y fecunda variedad". (ASALE 2010: x)

Estas tres citas dejan traslucir una tensión entre los niveles de jerarquía de las academias, que apela básicamente a la relación que se establece entre la RAE y sus pares. En el primer fragmento se afirma “como es lógico" que el "protagonismo” recaiga en las corporaciones americanas. También se señala, en el segundo extracto, que la RAE jugó un papel indispensable. Finalmente, se hace hincapié en que la tarea se efectúa en conjunto. Esto significa que la ASALE por sus propios medios no podría jamás haber llevado adelante la empresa, lo cual conduce inevitablemente a que se requiera el apoyo imprescindible de la RAE para lograr, de ese modo, realizar la tarea.

Sigue la "Introducción” firmada por Humberto López Morales, quien sintetiza la labor afirmando: "En este sentido, puede decirse con total honradez que las verdaderas autoras de este Diccionario de Americanismos son las academias americanas" (ASALE 2010: xxviii).

El bloque final está integrado por la "Guía del consultor", las tablas de "Abreviaturas, signos, familias lingüísticas y lenguas” y, por último, la sección de "Bibliografía”, con todas obras -llamativamente- de Humberto López Morales.

En lo que concierne al aspecto metodológico, se formularon determinadas líneas de acción y se moldearon herramientas ad hoc de acuerdo con los procedimientos vigentes de la tarea lexicográfica. En ese sentido, destacan la conformación de un corpus específico de textos para la construcción del lemario (vaciamiento de voces americanas del DRAE; preparación de la base de datos ARU para la consulta de 150 diccionarios de americanismos - generales y nacionales - publicados desde 1975) y el diseño de una planta inédita y original. La dinámica de trabajo, se explica, es un ida y vuelta entre Madrid y América: escritura de borradores en la sede central; envío 
de borradores a las academias correspondientes; revisión de los borradores, incorporación de correcciones y propuestas; y redacción artículos definitivos en Madrid. ${ }^{29}$ De acuerdo con lo declarado, el DA asume las siguientes características generales:

- Dialectal: La obra [...] es un diccionario del español de América. Se ocupa desde los Estados Unidos, hoy el segundo país hispanohablante del mundo por el número de sus hablantes, hasta Chile y la Argentina, en el extremo sur del continente. No se atiende a zonas vecinas, parcialmente ajenas al hispanismo, a pesar de que el forzoso contacto que han tenido y tienen con él las haya llevado a un importante acercamiento cultural y lingüístico [...].

- Diferencial: El DiCCIONARIO DE AMERICANISMOS es diferencial con respecto al español general. ${ }^{30} \mathrm{En}$ el plano léxico se entiende por «español general» el conjunto de términos comunes a todos los hispanohablantes (sol, cama, agua, comer...) bastante más del 80 por ciento de nuestro vocabulario-, independientemente de la variedad dialectal particular que se maneje. No se trata, pues, de establecer la contrastividad con el «español de España», como ha sido habitual hasta ahora.

29 Las academias americanas aportan, en una estructura ciertamente piramidal, los equipos de revisión local conformados por coordinadores (académicos de número de las respectivas corporaciones) y becarios. A lo largo del 2006 formé parte de la comisión argentina por haber sido graduada de la Escuela de Lexicografía Hispánica.

30 En el libro del proyecto (AAL, 2005 ver supra) no aparecía el sintagma "español general”, sino "español de España": "Es un diccionario dialectal —el español de América-y diferencial con respecto al español de España. Quedarán fuera de las páginas del $D A A$ los términos que, aunque nacidos en América, se usen babitualmente en el español europeo" (69) [la negrita es nuestra]. Hay que señalar, sin embargo, que aun cuando se cambie el nombre de la variedad, la política se mantiene debido a que hay un solapamiento ideológico entre los términos “español general” y "español de España". Dichas nociones resultan funcionales a la construcción de un discurso igualador de formas lingüísticas diversas que habilite la aparición de un modelo lingüístico "representativo" (presente en el nuevo lema académico: "unidad en la diversidad"). El discurso de la igualdad es la forma de opacar (en términos de Bourdieu ([1985] 2008), de hacer "anónima") una forma lingüística, en rigor, impuesta. 
[...] Quedan fuera de las páginas del DiCCIONARIO DE AMERICANISMOS las palabras que, aunque nacidas en América, se usan habitualmente en el español general y aun en otras lenguas (chocolate, canoa, tomate, etc.).

- Descriptivo: El Diccionario de Americanismos carece de propósito normativo. No da pautas para el «bien hablar o escribir», ni silencia términos considerados por la comunidad (aunque cada uno tiene los suyos) como malsonantes, tabuizados, vulgares, extranjerismos, neologismos, ni palabras que aluden a cuestiones de sexo-género, procedencias, defectos físicos o morales, ni términos de la drogadicción, el narcotráfico, la delincuencia, etc., que pudieran herir alguna susceptibilidad. [...].

- Usual: Este Diccionario es usual, por lo que recoge términos - sea cual sea su significado- con gran frecuencia de uso manejados en la actualidad; también otros cuya frecuencia de uso es baja, más los que han sido atestiguados como obsolescentes, si bien en estos dos casos van caracterizados puntualmente con la marca respectiva. Sin embargo, la colecta de términos que componen el DICCIONARIO DE AMERICANISMOS ha tenido que ser selectiva, dado el espacio limitado del que se disponía. Nuestra esperanza es que las Academias americanas de la Lengua Española emprendan en breve tiempo la elaboración de una serie de diccionarios nacionales que les permita dar cabida en ellos a aquellos términos que no han podido entrar en estas páginas, de manera que quede reflejado todo lo rico, amplio y variado que es el panorama léxico americano.

- Descodificador: El DicCionario de Americanismos es también descodificador y por ello está diseñado para ayudar al usuario a entender cualquier unidad textual de ese enorme corpus con que hoy cuenta Hispanoamérica, y, también, naturalmente, textos orales. 
Lauria • La política lexicográfica actual de las academias de la lengua española 291

- Actual: El radio de acción del Diccionario de americanismos abarca aproximadamente los últimos cincuenta años (ASALE 2010: XXXI-XXXII).

Asimismo, en cuanto al metalenguaje en el que deben redactarse los enunciados definidores, se manifiesta:

Las definiciones del DicCionario de Americanismos son lexicográficas, no enciclopédicas, ya que la presente obra es un diccionario de palabras, no un diccionario de cosas.

En todo momento se han preferido las definiciones propias, con la circunstancia de que no marcamos con letra cursiva los complementos que impiden el cumplimiento de la ley de sinonimia, es decir, el éxito de la operación de sustitución.

Las definiciones son neutras, objetivas, sin valoraciones de ningún tipo ni puntos de vista particulares que reflejen una determinada posición o ideología.

Las definiciones son claras y precisas, para lo cual se ha cuidado especialmente que la lengua utilizada en ellas sea un español estándar. Todo el vocabulario que se maneja al redactar las definiciones está contenido en el mismo DICCIONARIO DE AMERICANISMOS o en el DRAE. (ASALE 2010: XLV)

En algunos casos, vale subrayar, se coloca directamente un equivalente en la definición y no una paráfrasis. Son representativas las siguientes muestras:

carro.

I. 1. m. EU, Mx: N, S, Gu, Ho, ES, Ni, Pa, Cu, RD, PR, Co, Ve, Pe, Automóvil. $(\ldots)$

carrousel.

I. 1. m. EU, Ho, Ni, Ch, Carrusel, tiovivo.

vos.

1. pron. Mx:SE, Gu, Ho, ES, Ni, Co:O, SO, Ve:O, Ec, Bo, Py, Ar, Ur, Ch, pop. Tú. (...) 


\subsection{Definición y delimitación de los americanismos léxicos}

Una gran problemática es aquella que incumbe a los criterios de definición (alcance, tratamiento y límites) de lo que se entiende por americanismo en el plano léxico y, por tanto, se incluye (o se excluye) en el repertorio. Este se preocupa por expandir la noción de uso y convertirse, así, en una herramienta con fines instrumentales más que simbólicos, adecuado a las prácticas concretas de intercambio comunicativo en un espacio vasto y diverso, a la lectura y traducción de textos literarios y no literarios, al doblaje de películas y programas de televisión, y al aprendizaje de español.

El DA concibe como americanismos voces de distintas clases: los lexemas autóctonos de América y sus derivados, creaciones originales americanas, criollismos morfológicos, lexemas de procedencia española con cambio o especificación de contenido semántico, arcaísmos españoles vivos en América, lexemas procedentes de otras lenguas tanto antiguos como recientes en el español americano (con su ortografía original a menos que exista una variante hispanizada bastante extendida, calco, adaptación fonológica-gráfica o fonológica y morfológica), acrónimos y nombres propios lexicalizados, y frases proverbiales.

La implementación de políticas lingüísticas desde España, que cuentan con el consentimiento de ciertos sectores de la intelectualidad americana a fin de mantener e imponer una jerarquía lingüística geográfica y social, coadyuvó a la permanencia de los efectos de la memoria de la colonización lingüística en la larga duración:

Los efectos ideológicos de la colonización se materializan en consonancia con un proceso de colonización lingüística, que supone la imposición de ideas lingüísticas vigentes en la metrópoli y un imaginario colonizador enlazando lengua y nación en un proyecto único. (Mariani 2004: 25) [La traducción es nuestra $]^{31}$

31 Sobre la descolonización lingüística, ver Horta Nunes (2008) para el caso de la lexicografía brasileña. 
Dichos efectos anclan en una trama de diferenciación imprecisa que desdobla en dos a la lengua: el español de España y el español de América comprendido como un cuerpo unitario y uniforme. Este último se entiende a través de rasgos generales (americanismos) o particulares (argentinismos, colombianismos, mexicanismos), calificados como desvíos desde una impronta normativa o como particularidades desde una mirada descriptiva. Dicho de otro modo, se trata de perpetuar, como bien afirma Lara (2012), la distinción entre un español central y uno periférico (pese al reconocimiento del peso demográfico de América). Parece que a las academias les cuesta reconocer los argumentos científicos que superan la dicotomía metrópoli/colonia (subalternidad) en cuestiones lingüísticas. El DA se inscribe, así pues, en una matriz de sentidos que regula lo que puede y debe ser dicho con respecto a la lengua española a través de un método diferencial, con un alcance léxico selectivo usual pero pancrónico y sin reparar en las zonas de contacto y regiones de frontera: la existencia de un centro y de una periferia que posee -ismos, a pesar de los discursos remozados, los cambios de lemas y los aparentes giros políticos y teórico metodológicos en la definición de la norma y en la producción de los instrumentos lingüísticos, entre ellos muy particularmente el diccionario monolingüe.

En el español "trasplantado" a América se produce un encuentro de la lengua de colonización con otras (lenguas indígenas, lenguas vecinas, lenguas extranjeras, lenguas de inmigración), pero también se produce un lento desencuentro con ella misma. El español trajo la memoria lingüística europea, pero la propia experiencia histórica, en función del contacto/conflicto con otras lenguas y merced a la propia formación histórico social en unos territorios distintos y lejanos, la fue filiando a memorias heterogéneas. Es a raíz de ello que se cuestionan por ambiguas y, eventualmente, inconsistentes ${ }^{32}$ las categorías

\footnotetext{
32 ¿Vale la pena preguntarse cuál fue el criterio en el que se asentó la praxis lexicográfica para recoger voces en función de los grados de frecuencia y dispersión geográfica? Es decir, ¿en cuántos países debía usarse? La respuesta es amplia: en un solo país, en un grupo de países o en todos. Nada emana en cuanto a los llamados "panamericanismos" por su presencia generalizada en (casi) todo el territorio:
} 
fijadas de americanismos: si se incluyen los indigenismos, voces autóctonas de América, ¿por qué entonces no se incorporan las acepciones más usuales de canoa o tomate? Si se incluyen las creaciones originales americanas y criollismos morfológicos, ¿por qué entonces no se incorpora la voz chocolate y sí ballenato o corrido? ¿Qué diferencias hay entre esos vocablos? En ambos casos no hay otra forma de nombrar al referente y se emplean, en consecuencia, en el llamado “español general”. La categoría “arcaísmos españoles vivos en América” se instaura sobre el punto de referencia de España y ya no del camuflado “español general”. ¿Qué es entonces lo que se enlista y describe? ¿Será acaso solo aquello vinculado con el color local? En lo sucesivo, el análisis del discurso lexicográfico despejará la cuestión.

\subsection{Análisis del discurso lexicográfico}

Tradicionalmente los diccionarios han tenido como efecto de sentido el de un saber estable, con una aparentemente escasa variación a lo largo del tiempo. Se los concibe, en general, como textos que parecen representar la supuesta unidad de la lengua que describen y registran, siempre igual a sí misma. El texto lexicográfico (las voces que se consignan y las definiciones que se presentan), sin embargo, no remite de manera directa a realidades unívocas e incontrovertibles, sino que comporta una dimensión ideológica vinculada con las condiciones de producción en las cuales se formula tanto las circunstancias de enunciación (quién, a quién, cuándo, dónde) como el contexto sociohistórico más amplio (aspectos políticos, económicos, educativos, culturales, demográficos, tecnológicos y científicos). Los diccionarios son, entonces, construcciones que rescatan momentos de las comunidades en las cuales se forjan y para las que están dirigidas. Constituyen, de este modo y pese al

\section{celular.}

I. 1. m. EU, Mx, Gu, Ho, ES, Ni, CR, Pa, Cu, RD, PR, Co, Ve, Ec, Pe, Ch, Py, Ar, Ur, Bo, pop. Teléfono portátil que se conecta a una central mediante ondas hercianas. (cel) (...) 
hecho de que en la larga duración presentan una notable estabilidad genérica (partes en que se dividen, categorías que utilizan, organización de las secuencias que exhiben, sistema de marcas y tipos de contextualización que emplean, etc.), discursos donde se asoman y se esconden sistemas lingüístico-político-histórico-ideológicos que activan (y apagan) determinados lugares de la memoria.

$\mathrm{Ha}$ quedado claro que el DA es diferencial con respecto al español general almacenado en el DRAE. Empero, “(...) la colecta de términos que componen el DICCIONARIO DE AMERICANISMOS ha tenido que ser selectiva, dado el espacio limitado del que se disponía" (ASALE 2010: XXXII). Por lo tanto, incluye una selección que, pese a eso, busca exhibir una idea de completud. Constituye, de este modo, un recorte extraído no se sabe bien de dónde (datos empíricos, fichas lexicográficas artesanales, fuentes secundarias como otros diccionarios). ${ }^{33}$ Si fuera el caso de que emana de los materiales que conforman el corpus, ${ }^{34}$ hay que subrayar que estos no están disponibles públicamente $\mathrm{y}$, en consecuencia, desconocemos su procedencia geográfica, social, genérica y de registro. La escueta alusión a la base ARU no proporciona mucha información.

Si bien hay un corrimiento hacia un polo científico, procurando una ilusión de objetividad, buscando neutralizar influencias, reprimiendo el recorte acometido y, con ello, elidiendo su condición

33 El hecho de que se hayan volcado en el DA muchos de los diccionarios de -ismos (nacionales y generales) afianza la hipótesis de que se abastece mayormente de elementos del folclore y que el léxico consignado esté bastante alejado de las prácticas lingüísticas reales y efectivas de los hablantes.

34 El uso de un corpus de datos es el único inventario capaz de nutrir metódicamente a la lexicografía actual con los vocablos que componen una nomenclatura basada en la realidad social y en el uso efectivo de la lengua. El corpus no solo es esencial para establecer los significados de las entradas, su comportamiento sintáctico en contexto y sus posibles valores pragmáticos y estilísticos, sino también para jerarquizar las acepciones, elaborar las definiciones y proveer los ejemplos que ilustran los usos. Sirve, asimismo, para hacer estudios cuantitativos de frecuencia de uso y de dispersión geográfica, situacional y social de los vocablos, que lleven a una determinación apegada a la realidad de las marcas de uso de las palabras. En suma, la explotación de un corpus es una vía opuesta a la construcción de un modelo lingüístico con criterios, muchas veces, preestablecidos que la obra solo se limita a constatar, tal como lo ha hecho el DRAE históricamente. 
política, se debe reparar en que la selección de entradas es su punto álgido. Las formas escogidas (o descartadas) sintonizan con intereses sesgados al compás de una gama de demandas y se alejan de las pautas metalexicográficas vigentes. El DA no escapa a las determinaciones ideológicas del momento, la sociedad y la comunidad discursiva en la que se fragua.

El examen de la letra $c^{35}$ revelará los campos léxicos predominantes, lo que redundará en conocer las discursividades que lo atraviesan. En primer lugar, se observa que las clases de palabras son, en su gran mayoría, léxicas (sustantivos, adjetivos y verbos) frente a las gramaticales (conjunciones, preposiciones, pronombres, etc.). Se exceptúan las interjecciones (¡caballada!, ¡caché!, ¡cachucha!). Esto obedece a que la función de las formas diccionarísticas parciales es la comprensión por sobre la producción, finalidad propia de la lexicografía integral. Así pues, se vislumbran continuidades con la tradición de diccionarios de americanismos comprometida en coleccionar vocabulario concerniente a flora (caá, cabrauyo, cabuya); fauna (cabaicucho, caballa, caballerote); frutas y verduras (cacbimbola, caimarona, calabacita); oficios (caballerango, a; cabañero, a; cabaretista); fenómenos naturales y climáticos (cabañuelas, cachuera, cacimba); partes del cuerpo humano, especialmente las formas consideradas tabú de los órganos genitales (cable, cacerola, cachete); platos y bebidas típicos (cacaito, cachanga, cachapa); vestimenta y calzado (cachetero, cachuncho, calamorro); juegos y manifestaciones culturales o artísticas autóctonos (cabra, cabrerillo, cacerolazo, cachaca); artículos y utensilios de uso cotidiano (cabezal, cabo, cabresto); enfermedades (cacarañica, cagatina, cagazón); entre otros, para los sustantivos. Cualidades, virtudes y defectos intelectuales, físicos y "morales" (caballo, cabeceburro, a; cabecipelado, a; cacatúa), entre otros, para los adjetivos. Asimismo, acciones de la vida de todos los días (cabecear, cabrear(se), cacharrear(se), cachear) para los verbos.

35 La decisión de tomar la letra c para conformar la muestra obedece a que se trata de la letra más productiva en posición inicial de palabra. Su sola consideración supera ampliamente el 10\% del lemario total del diccionario, con lo cual estaría asegurada la representatividad conforme lo expresado en Bukowska (2010). 
En segundo lugar, surgen dos cuestiones ligadas: de un lado, el carácter usual y actual, y, del otro, la dicotomía rural/urbano. Acerca de la primera, el DA declara que su radio de acción abarca aproximadamente los últimos cincuenta años. En paralelo, manifiesta que "recoge términos [...] con gran frecuencia de uso manejados en la actualidad" (ASALE 2010: XXXII) a los que añade aquellos cuya frecuencia de uso es baja y los obsolescentes, aunque estos dos últimos casos carguen la marca de uso correspondiente (p. us. (cabedor, ra; cabrillazo, cacero, ra) y obsol. (caballería, cabinero, ra; cabuyería)). Claro que, en ocasiones, dichas voces se enlazan con la marca rur. (cabronear, cabulista, cachada). Pese a la existencia de la etiqueta urb., se detectó su casi nula presencia (v.g. calote), puesto que son, todo indica, las formas no marcadas. Quiere decir esto que se ponen de relieve las escenas definidoras urbanas en contraste con el mundo del campo y las prácticas del pasado asociadas a la vida rural.

A diferencia de otras obras que componen la serie, llama la atención la sutil pero indicadora cantidad de voces y acepciones del léxico juvenil. ${ }^{36}$ Como se sabe, los términos asociados con la variable generacional (cronolectos) tienen una vida que puede ser efímera, puesto que cambian con mucha velocidad y, por esta razón, se estudian con recelo antes de compilarlos en un repertorio (criterio que asume, por ejemplo, el DRAE). En el DA se concentran alrededor de campos de bienes de consumo cultural como música, cine, series y programas de televisión (carrete, cartoon, chanchullo, chupe, cool, cover), relaciones afectivas y de amistad (catrenol, chacobeo, choting, cocowash), tribus sociales (caco; cheto, a; chuntarro) y nuevas tecnologías (chatear, chateador).

En tercer lugar, en lo atinente a los neologismos y extranjerismos hay varios aspectos para destacar. Numerosas voces neológicas provienen de fuentes de creación léxica como los desarrollos

\footnotetext{
36 Por supuesto que el discurso de la microestructura (de los distintos segmentos que la componen: enunciado definidor, sistemas de marcas, orden de las acepciones) acompaña la orientación argumentativa de la selección del lemario. En efecto, la inclusión de las marcas de registro est. (estudiantil) y juv. (juvenil) da cuenta del léxico "manejado por subgrupos de la comunidad de habla".
} 
científicos y técnico tecnológicos (primordialmente los dispositivos informáticos y de comunicación: carrier, cartridge, cd móvil, celular, chancar(se), cleaner, computador, computadora); el turismo (chartear, checar, chequear, counter); la publicidad, el cine y la televisión (cherry, chivo, chopper, clearance, close up, comercial, cortina musical); los deportes (cachear, campo corto, canopy, charging, chutear(se), coach, court); el ocio (diversión y entretenimiento), las actividades sociales y el bienestar (casual, casual day); y los sectores comercial y financiero (cash, clearing, cluster, COD). En lo que a los extranjerismos se refiere, tema, como se nota, estrechamente fundido con el anterior, en los casos en que se mantiene su ortografía original, son tratados como elementos externos en tanto se resaltan con cursiva y comportan el respectivo paréntesis etimológico, puesto que no son "de procedencia patrimonial española" (ASALE 2010: XL). Esto corre tanto para las unidades procedentes de lenguas europeas como para los indigenismos. Del grupo de las primeras, hay una presencia abrumadora de anglicismos, que se confinan, en gran medida, a los mismos campos léxicos que los neologismos. Tanto unos como otros se articulan con la estructura social: ambos, en general, surgen de los sectores cultos. Mientras que los primeros se especializan en aportes de orden intelectual, los segundos se circunscriben mucho más a lo material. Debido a la influencia que ejercen los medios de comunicación en la actualidad, estos se difunden velozmente por todas las clases sociales.

En síntesis, se advierte, así, que el discurso del lemario presenta recurrencias y desplazamientos con respecto a la matriz de los diccionarios de americanismos. Nos referimos a recurrencias porque se siguen consignando voces de los campos léxicos tradicionales, marcados por la impronta folklórica, y desplazamientos porque ingresan levemente voces de ámbitos asociados con discursividades juveniles, (pos)modernas, contemporáneas y urbanas. Esto último nos traslada a la próxima sección, ya que sorprende que sean los mismos espacios donde opera el léxico global por presión de los mercados neoliberales. 
5. Posiciones glotopolíticas: americanismos y la globalización del léxico hispánico

Dada la concepción hegemónica actual de lengua como mercancía se desencadena la noción de lengua global. Una de las principales repercusiones glotopolíticas de la globalización es la producción, comercialización y distribución de las industrias culturales, de la lengua y editorial en un mercado unificado más rentable, es decir, en un territorio amplio que exceda los límites nacionales, esto es, las áreas idiomáticas. Con el fin de aglutinar el mercado transnacional, se suavizan e incluso se borran los trazos locales o regionales, y se acentúa, así, la desterritorialización de la lengua. Esta ideología lingüística transgrede la regla número uno del Estado nación, que ponía énfasis en el territorio así como en la identidad propia y diferenciadora, acorde a la era de los mercados internos cerrados y proteccionistas.

En el caso del español, uno de los ideólogos o, mejor dicho, language makers en la terminología de Roy Harris (1980) es el ya mencionado Humberto López Morales, quien con su libro La globalización del léxico hispánico ensaya, desde la sociolingüística, una explicación del fenómeno a la vez que interviene en procesos político ideológicos sobre la lengua. Para el autor, el español global (o español internacional), que se empieza a imponer a partir del CILE de Valladolid (2001) y se afianza en el CILE de Rosario en el 2004, es una modalidad compartida, sobre todo, por los hablantes cultos y posee gran riqueza léxica. No es, para nada, comparable al español neutro, asociado a una creación artificial y al empobrecimiento y la simplificación idiomáticos. Tampoco supone una amenaza para las identidades locales. Se corresponde, más bien, a un proceso que discurre "naturalmente", connotado positivamente, en el que los hablantes cultos conocen el "término neutralizador de la lengua general” aunque no suelan usarlo en el estilo espontáneo. El hecho de que sea fruto de un "consenso" y que permita "unificar la lengua sin uniformizarla" es la clave sobre la que el académico monta su argumentación. El español global es la variedad destinada 
a los ámbitos mediáticos transhispánicos. Más que reveladora es, en este sentido, la siguiente cita: "En el estado actual de nuestras comunicaciones no se deberían volver a repetir casos como los de computadora / ordenador y de [teléfono] celular / móvil, por ejemplo” (López Morales 2006: 183).

Ahora bien, como se explicó en la introducción, la globalización lingüística implica necesariamente la emergencia de fuerzas locales, es decir, genera situaciones de glocalización que apuntan en dos direcciones no dicotómicas sino dialécticas (Niño-Murcia, Godenzzi y Rothman 2008). Hacia lo global (en términos de expansión, comunicación en espacios amplios, unidad y homogeneidad) y hacia lo local (en términos de contracción, identidad local, diversidad), se asume que el sentido histórico del DA, en tanto forma parte de una estrategia de política lingüística imperialista, debe comprenderse en ese cruce. Vamos por partes: el léxico global, desterritorializado, se alinea con mandatos económicos de empresas transnacionales para captar y cubrir un mercado extenso. El léxico local, por su parte, carga un sello territorial concreto, la particularidad. En palabras de Ortiz, "para esquivar las fallas del mercado" se deben burlar las contradicciones que separan lo local de lo global (2014: 161). El imaginario del consumo requiere lo común. Sin embargo, la diversidad también es necesaria para vender. Las empresas multinacionales ligadas a las economías de servicios en varios rubros (bancos, finanzas y seguros; comunicaciones y nuevas tecnologías; explotación del turismo; industrias culturales, de la lengua y editorial; venta telefónica) se mueven entre la unidad y la diversidad para atraer y seducir a los clientes. El DA responde con indicios tenues a estas imposiciones. Aunque no abandona el sesgo folklórico que identifica como género a los diccionarios generales de americanismos, no es aventurado señalar que se arrima a un repertorio anclado en el registro y definición de bienes y servicios de consumo contemporáneos, por lo que resignifica la idea de “americanismo".

No se trata, en definitiva, de dos posiciones glotopolíticas con tácticas encontradas, como podría pensarse, sino complementa- 
rias y entramadas, cuyo objetivo final abreva en conquistar - no solo pero principalmente- el mercado promisorio en español en los Estados Unidos. La población hispanohablante creció considerablemente en los últimos años. Es, en efecto, la comunidad más numerosa entre los grupos minoritarios, hecho que la convierte en una potencia económica por la capacidad adquisitiva que representa. El mercado en español es de progresiva relevancia para los planes de la industria y para alentar el consumo. De hecho, son justamente en las áreas de las industrias culturales y de servicios donde se mide la proyección del español en ese país. Esto justifica las acciones del dispositivo académico con el fin de controlar su expansión y obtener los beneficios a través de la codificación: consolidar la visión de la lengua como "general”, acompañada de un bloque americano salpicado de localismos, incluidos los de los EEUU (aparece en el DA la marca diatópica EU), por los diversos orígenes nacionales que conforman la población hispanohablante. ${ }^{37}$

\section{A modo de conclusión}

El análisis glotopolítico del DA revela, primero, lazos con cambios provocados en el orden socioeconómico actual. Esto se observa en la configuración del discurso del lemario, ya que, sin cesar de registrar el vocabulario folklórico y popular, consigna moderadamente un nuevo tipo de léxico que convoca un imaginario social más amplio afín a los tiempos que corren.

Segundo, no se producen "puntos de fuga", desviaciones en la representación de las normas léxica y lexicográfica de los americanismos, categoría que se presenta como algo evidente, que, por ende, no se problematiza, obturando la reflexión y reproduciendo la afirmación de un "español general" y un bloque americano. Por lo dicho, los destinatarios serán —no solo, pero también- los

\footnotetext{
37 Humberto López Morales coordinó, en 2008, el Anuario del IC “Enciclopedia del español en los EEUU”. Para una mirada crítica sobre el español en los Estados Unidos, ver Del Valle (2011).
} 
lingüistas; traductores; especialistas en lengua, literatura y cultura; historiadores; profesores y alumnos de español como lengua materna, segunda y extranjera; pero también se agregarán quienes se dedican al marketing y capacitan "lengua de obra” (Arnoux y Bein 2015) para hacer más lucrativos sus emprendimientos comerciales.

Tercero, el DA es un nudo en la red de instrumentos lingüísticos y discursos metalingüísticos que predican sobre el español trazados como parte de un programa de gestión de lengua desde las academias que se pretende científico, basado en saberes especializados y presentado como ideológicamente neutro pero que, en realidad, encubre y consolida intereses económicos de sectores dominantes. Pese a que las obras son corporativas, hay nombres de autor correlativos a proyectos. En este caso, López Morales desempeña un papel nodal. Sus aportes están al servicio de una determinada política sobre el léxico.

En definitiva, el atractivo de analizar diccionarios desde el enfoque glotopolítico reside en que en su confección se cristaliza el resultado de múltiples factores de compleja articulación que entran, muchas veces, en tensión: mutaciones en la composición de la población, cambios en la distribución de las fuerzas políticas, exigencias sociales y económicas, necesidades del mercado laboral, consideraciones pedagógicas vigentes, demandas educativas, desarrollos en las tecnologías de la palabra, avances en las Ciencias del Lenguaje, entre otros.

\section{Corpus}

Asociación de Academias de la Lengua Española

2010 Diccionario de americanismos. Lima: Santillana.

Asociación de Academias de la Lengua Española y Real Academia ESPAÑOLA

2004 La nueva política lingüística panbispánica. S/d.

INSTITUTO CERVANTES

2009 Enciclopedia del español en los Estados Unidos. Coord., Humberto López Morales. Madrid: Santillana. 
López Morales, Humberto

2005 Diccionario académico de americanismos. Presentación y planta del proyecto. Buenos Aires: Academia Argentina de Letras.

2006 La globalización del léxico hispánico. Madrid: Espasa.

Real Academia Española

s/a Diccionario de americanismos. Consultado: 27 de julio de 2015. <http://www.rae.es/obras-academicas/diccionarios/ diccionario-de-americanismos $>$.

\section{Referencias bibliográficas}

Arnoux, Elvira

2008a Los discursos sobre la nación y el lenguaje en la formación del Estado (Chile, 1842-1862). Estudio glotopolítico. Buenos Aires: Santiago Arcos.

2008b “'La lengua es la patria', 'nuestra lengua es mestiza' y 'el español es americano’: desplazamientos significativos en el III Congreso de la Lengua Española”. En Más allá de la nación. Ed., Sabine Hofmann. Berlín: Edition Tranvía, 17-39.

2010 "Reflexiones glotopolíticas: hacia la integración sudamericana”. La regulación politica de las prácticas lingüísticas, 329-360.

2011 "Hacia una definición de las políticas lingüístico-educativas del Estado Argentino". En Para una política del lenguaje en Argentina. Ed., Lía Varela. Caseros: EDUNTREF, 35-55.

2014 "En torno a la Nueva gramática de la lengua española (Real Academia Española y Asociación de Academias de la Lengua Española)". En Temas de glotopolítica. Eds., Elvira Narvaja de Arnoux y Susana Nothstein. Buenos Aires: Biblos, 245-270.

Arnoux, Elvira Narvaja de y Roberto BeIN

2010 La regulación politica de las prácticas lingüisticas. Buenos Aires: Eudeba.

2015 Políticas lingüisticas y enseñanza de lenguas. Buenos Aires: Biblos.

Arnoux, Elvira Narvaja de y José Del Valle

2010 "Las representaciones ideológicas del lenguaje. Discurso glotopolítico y panhispanismo”. Spanish in Context. 7, 1, 1-24. https://doi.org/10.1075/sic.7.1.01 nar 
Arnoux, Elvira Narvaja de y Susana NothSTEIN

2014 Temas de glotopolítica. Buenos Aires: Biblos.

BAUMAN, Zygmunt

1999 La globalización. México D.F.: Fondo de Cultura Económica. 2005 Identidad. Madrid: Losada.

Bourdieu, Pierre

[1985] 2008 ¿Qué significa hablar? Madrid: Akal.

Buкоwska, Agnieszka

2010 "Sampling techniques in metalexicographic research". En Proceedings of the 14th EURALEX International Congress. Eds., Anne Dykstra y Tanneke Schoonheim. Leeuwarden / Ljouwert: Afûk, 1258-1269.

Calvet, Louis-Jean

[1974] 2005 Lingüistica y colonialismo. Buenos Aires: Fondo de Cultura Económica.

Cerrón-Palomino, Rodolfo

2010 "Acotaciones al Diccionario de americanismos". Lexis. XXXIV, 1, 161-176.

Chávez Fajardo, Soledad

2013 "Actitudes lingüísticas y glotopolítica en el español de Chile. Un enfoque diacrónico a través de los paratextos en codificaciones lexicográficas diferenciales (1875-2010)”. En Explorando estándares lingüisticos en variedades no dominantes de lenguas pluricéntricas. Eds., Rudolf Muhr et al. Nueva York: Peter Lang, 439-456.

2014 "Ideas lingüísticas presentes en diccionarios latinoamericanos del siglo XIX”. En Con una letra joven. Coords., Clara Grande et al. Salamanca: Universidad de Salamanca, 37-44.

Coll, Magdalena

2012 "Entre la fiscalización y el registro del español del Uruguay de finales del siglo XIX: el vocabulario de Daniel Granada y el glosario de Eduardo Acevedo Díaz”. En Por sendas ignoradas. Coord., José Luis Ramírez Luengo. Lugo: Axac, 11-31.

2015 "Prácticas lexicográficas e ideas lingüísticas en Benjamín Fernández y Medina”. Anuario de Letras. III, 1, 51-85. 
Del Valle, José

2007 La lengua, ¿patria común? Frankfurt / Madrid: Vervuert / Iberoamericana.

2011 "Política del lenguaje y geopolítica: España, la RAE y la población latina de Estados Unidos”. En El dardo en la palabra. Eds., Silvia Senz y Montse Alberte, 551-590.

2013a "Language, politics and history: an introductory essay". En $A$ Political History of Spanish. Ed., José Del Valle. Cambridge: Cambridge University Press, 3-20. https://doi.org/10.1017/ cbo9780511794339.002

$2013 \mathrm{~b} \quad$ "Linguistic emancipation and the academies of the Spanish language in the twentieth century: the 1951 turning point". En Del Valle 2013a: 229-245. https://doi.org/10.1017/ cbo9780511794339.019

Del Valle, José y Luis Gabriel-Stheeman

2004 La batalla del idioma: la intelectualidad bispánica ante la lengua. Frankfurt / Madrid: Vervuert / Iberoamericana.

Del Valle, José y Laura Villa

2012 "La disputada autoridad de las academias: debate lingüístico-ideológico en torno a la Ortografía de 2010”. Revista Internacional de Lingüistica Iberoamericana. X, 19, 29-53.

Fanjul, Adrián

2011 "Policêntrico e pan-hispânico. Deslocamentos na vida política da língua española”. En Políticas da norma e conflitos lingüisticos. Orgs., Xoán Carlos Lagares y Marcos Bagno. San Pablo: Parábola, 299-331.

García Canclini, Néstor

1999 La globalización imaginada. Buenos Aires: Paidós.

2004 Diferentes, desiguales y desconectados. Barcelona: Gedisa.

Glozman, Mara y Daniela Lauria

2012 Voces y ecos. Una antología de los debates sobre la lengua nacional (Argentina, 1900-2000). Buenos Aires: Cabiria / Biblioteca Nacional. 
GreussLich, Sebastian

2015 "El pluricentrismo de la cultura lingüística hispánica: política lingüística, los estándares regionales y la cuestión de su codificación”. Lexis. XXXIX, 1, 57-99.

Gutemberg Bohórquez, Jesús

1984 Concepto de americanismo en la historia del español. Bogotá: Instituto Caro y Cuervo.

GuZMán, Martín Luis

2010 Obras completas II. México D.F.: Fondo de Cultura Económica.

Habermas, Jürgen

[1998] 2000 La constelación posnacional. Barcelona: Paidós.

HaEnsCH, Günther

1986 "La situación actual de la lexicografía del español de América". Revista de Filología Románica. IV, 281-293.

1994 "Dos siglos de lexicografía del español de América: lo que se ha hecho y lo que queda por hacer”. En Unidad y variación léxicas del español de América. Eds., Gerd Wotjak y Klaus Zimmermann. Frankfurt/Madrid: Vervuert/Iberoamericana, 39-82.

Hamel, Rainer Enrique

2004 "Las cuatro fronteras de la identidad lingüística del español: lengua dominante y dominada, lengua fronteriza y lengua internacional". Consultado: 20 de agosto de 2015. <http:// congresosdelalengua.es/rosario/mesas/hamel_r.htm>.

Haroche, Claudine

1984 Faire dire, vouloir dire. Lille: Preses de l' Université de Lille.

HARris, Roy

1980 The Language-Makers. Ithaca, New York: Cornell University Press.

Huisa Téllez, José Carlos

2013 "La impronta política en la primera lexicografía hispanoamericana: republicanismo y antirrepublicanismo". Lexis. XXXVII, 2, 269-303.

2014 "Representaciones sociales a través del lenguaje en la lexicografía hispanoamericana decimonónica”. Boletín de Filología. XLIX, 2, 139-159. https://doi.org/10.4067/s071893032014000200007 
LARA, Luis Fernando

1996 "Por una redefinición de la lexicografía hispánica”. Nueva Revista de Filología Hispánica. XLIV, 2, 345-364.

1997 Teoría del diccionario monolingüe. México D.F.: El Colegio de México.

2004 Lengua histórica y normatividad. México D.F.: El Colegio de México.

2012 “Diccionario de americanismos”. Panace@. XIII, 36, 352-355. Consultado: 20 de agosto de 2015. <http://www.tremedica. org/panacea/IndiceGeneral/n36-plumero_LFLara.pdf.>.

2013 Historia mínima de la lengua española. México D.F.: El Colegio de México.

2015 Temas del español contemporáneo. México D.F.: El Colegio de México.

LAuria, Daniela

2011 "Apuntes para una historia de la producción lexicográfica monolingüe en la Argentina: etapas del proceso de diccionarización y modalidades diccionarísticas entre 1870 y 1910”. Boletín de Filología. XLVI, 1, 105-151. https://doi. org/10.4067/s0718-93032011000100004

2012a "La Academia Argentina de Ciencias y Letras y su posición sobre la lengua nacional (1873-1879)”. PRISMAS. Revista de Historia Intelectual (Dossier: "Sociabilidades culturales en Buenos Aires, 1860-1930: círculos, sociedades, ateneos y cafés”). 16, 171-174.

2012b "El primer diccionario integral del español de la Argentina: reflexiones acerca del alcance de «integral»". Linguas e Instrumentos Linguísticos. 29, 53-92.

2013 "Consideraciones glotopolíticas en torno a los diccionarios escolares del español”. Revista Digital de Políticas Lingüisticas. 5, 7-47.

2014 "La producción lexicográfica de la Academia Argentina de Letras: un análisis glotopolítico del Diccionario del habla de los argentinos (DiHA, 2003 y 2008)”. En Temas de glotopolítica. Eds., Elvira Narvaja de Arnoux y Susana Nothstein. Buenos Aires: Biblos, 1-322. 
LAuria, Daniela y María López García

2009 "Instrumentos lingüísticos académicos y norma estándar del español: la nueva política lingüística panhispánica”. Lexis. XXXIII, 1, 49-89.

López Morales, Humberto

2008 "Diccionarios generales de americanismos: ayer y hoy". Boletín de Filología. XLIII, 2, 259-280.

Mar-Molinero, Clare

2000 The Politics of Language in the Spanish-Speaking World: from Colonisation to Globalisation. London / New York: Routledge.

MARIANI, Bethania

2004 A Colonização Linguística. Campinas: Pontes.

Niño-Murcia, Mercedes, Juan Carlos GodenzZi y Jason Rothman

2008 "Spanish as a World Language. The Interplay of Globalized Localization and Localized Globalization". International Multilingual Research Journal. 2, 48-66. https:// doi.org/10.1080/19313150701766912

Nunes, José Horta

2008 "Os diccionarios portugueses e a descolonização linguística". Linguas e Instrumentos linguísticos. 20, 25-39.

OrTIZ, Renato

2009 La supremacía del inglés en las ciencias sociales. Buenos Aires: Siglo XXI.

2014 Universalismo / Diversidad. Buenos Aires: Prometeo.

PAfFey, Darren y Clare Mar-Molinero

2009 "Globalisation, linguistic norms and language authorities: Spain and the Panhispanic Language Policy”. En Español en Estados Unidos y otros contextos de contacto. Eds., Manuel Lacorte y Jennifer Leeman. Frankfurt / Madrid: Vervuert / Iberoamericana, 159-173.

PAyer, Maria Onice

2005 "Linguagem e sociedade contemporânea - sujeito, mídia, mercado". Rua. 11, 9-25. 
Rama, Carlos

1982 Historia de las relaciones culturales entre España y la América Latina. Siglo XIX. México D.F.: Fondo de Cultura Económica.

Rizzo, María Florencia

2014 “Antecedentes de la política lingüística panhispánica: los congresos de la lengua española”. En Temas de glotopolítica. Eds., Elvira Narvaja de Arnoux y Susana Nothstein. Buenos Aires: Biblos, 191-220.

RojAs, Darío

2014 "Diccionario y estandarización lingüística en Hispanoamérica: la visión de Ramón Sotomayor Valdés (1866)”. Estudios Filológicos. 53, 109-121. https://doi.org/10.4067/ s0071-17132014000100007

2015 "Ideologías y actitudes lingüísticas en el Chile del siglo xIx: los reparos de Andrés Bello a las Correcciones lexicográficas de Valentín Gormaz”. Lexis. XXXIX, 1, 163-181.

RonA, José Pedro

1969 “Qué es un americanismo?”. En El Simposio de México. México D.F.: Universidad Nacional Autónoma de México, 135-148.

Senz, Silvia y Montse Alberte

2011 El dardo en la palabra. Barcelona: Melusina.

SePúlveda, Isidro

2005 El sueño de la madre patria. Madrid: Marcial Pons.

STEGER, Manfred

2009 Globalization. Oxford: Oxford University Press.

Weinberg, Félix

1976 “Un olvidado vocabulario americanista de 1853". Thesaurus. XXXI, 3, 442-480.

WERNER, Reinhold

1990 Amerikanismenwörterbücher des Spanischen und Wörterbücher des Spanischen Amerikas. Spezifische Probleme der Auswabl und Darbietung lexikographischer Information. Tesis de habilitación. Erlangen. 
1994 “QQué es un diccionario de americanismos?”. En Unidad y variación léxicas del español de América. Eds., Gerd Wotjak y Klaus Zimmermann. Frankfurt / Madrid: Vervuert / Iberoamericana, 9-38.

2001 “Áreas pendientes en la lexicografía del español americano". Consultado: 10 de agosto de 2015. <http://cvc.cervantes.es/ obref/congresos/valladolid/ponencias/unidad_diversidad_ del_espanol/2_el_espanol_de_america/werner_r.htm $>$.

ZimMERMANN, Klaus

2003 "El fin de los diccionarios de mexicanismos, colombianismos, argentinismos, cubanismos etc.”. Revista Internacional de Lingüística Iberoamericana. I, 1, 71-83.

2012 "Diccionarios, identidad e ideología lingüística”. Revista Internacional de Lingüistica Iberoamericana. X, 19, 167-181.

2013 "El papel de los diccionarios diferenciales y contrastivos en la estandarización de variedades nacionales en un español pluricéntrico". En Explorando estándares lingüisticos en variedades no dominantes de lenguas pluricéntricas. Eds., Rudolf Muhr et al. Nueva York: Peter Lang, 99-114.

Recibido: $16 / 05 / 2016$ Aceptado: 28/03/2017 